\title{
Comparative Study on (Non-)Destructive Techniques for On-Site Strength and Durability Assessment of Limestone Based Concrete Slabs
}

\author{
Bart Craeye $^{1,2}$, Daan van Keijzerswaard ${ }^{1}$ and Patricia Kara De Maeijer ${ }^{1}$
}

\author{
${ }^{1}$ Energy \& Materials in Infrastructure \& Buildings (EMIB), Faculty of Applied Engineering, \\ University of Antwerp, Campus Groenenborger, 2020-Antwerp, Belgium, bart.craeye@uantwerpen.be \\ ${ }^{2}$ Durable (re-)Building in Team (DuBiT Research Core), Department of Industrial Sciences \& \\ Technology, Odisee University College, Campus Aalst, 9300-Aalst, Belgium, bart.craeye@odisee.be
}

\begin{abstract}
For rehabilitation of existing concrete structures, strength and durability related properties of the reinforced element are of high importance. Assessment of these properties of existing structures can be performed by (i) destructive testing of drilled cores and testing the extracted samples in lab environment and (ii) indirect methods by using non- or semi-destructive techniques on site. The use of core-drilling is a time-consuming and labour-intensive method that weakens the existing concrete structure, leaving a lasting impression on it. As an alternative, many different non and semi-destructive techniques are available for the in-situ determination of compressive strength and durability related properties. An experimental program is conducted on concrete slabs of different strength classes intended for various exposure classes (according to EN206), based on a limestone aggregate matrix, which is typically used for Belgian applications. The plates have an age of approximately 5 years, which were also characterized at younger stage (in 2014). Besides destructive core drilling and testing (compressive strength tests, chloride migration testing, and determination of carbonation rate), several non-destructive techniques were selected for this study: the rebound hammer, the ultrasonic pulse velocity tester, the Wenner probe for concrete resistivity and the air permeability tester. Best fit correlations between the output of these different techniques were established. The effect of age (e.g. carbonation) on the established predictive models is being evaluated.
\end{abstract}

Keywords: DT vs. NDT, Strength, Durability, Transport Properties, Age Effect.

\section{Introduction}

For characterization of existing concrete structures, insight in the strength and durability related properties are necessary in order to come to an adequate rehabilitation or repair strategy (Hobbs et al. (2007)). Assessment of these properties can be performed by (i) time-consuming and labour-intensive destructive testing of drilled cores and testing the extracted samples in lab environment and/or (ii) indirect methods by using non- or semi-destructive techniques on site, as an alternative. In this study, an experimental program was conducted on concrete slabs with an approximate age of 5.5 years, intended for various exposure classes (variation in W/C-ratio, cement type and cement content), based on a limestone inert matrix, and frequently used for Belgian applications. These slabs were intensively investigated, both in 2014 and 2019, by means of destructive testing (compressive strength tests, chloride migration testing, and determination of carbonation rate), and non-destructive techniques: the rebound hammer, the ultrasonic pulse velocity tester, the Wenner probe for concrete resistivity and the air permeability tester. Best fit correlations between the output of these different techniques were 
established. The effect of age (e.g. carbonation) on the established predictive models is being evaluated.

By measuring the propagation speed of ultrasound waves through the material, the concrete quality is investigated. A high pulse velocity will result in a good quality concrete and, therefore, a higher compressive strength and more durable material can be expected. In this study, only ultrasonic techniques were used to determine to ultrasonic pulse velocity (direct transmission), according to EN 12054-4. The main influencing parameters on the output of the UPV are the type, content and hardness of the aggregates, the presence of cracks/voids in the structure and the moisture content of the concrete (Breysse (2012)). The W/C-ratio also affects the readings in pulse velocity. Furthermore, relative humidity also influences the output. The pulse velocity might increase up to $5 \%$ between dry and saturated test specimens, according to Solís-Carcaño et al. (2008).

The rebound hammer measures the rebound of a spring-loaded mass impacting on the surface of a concrete sample or structure, generating the rebound number, according to EN 12504-2. The higher this number, the harder the surface, indicating a high concrete compressive strength. A correlation exists between the compressive strength of standard cubes and the rebound number obtained by the hammer. However, this correlation is not universal and has to be modified for different devices, different concrete mixes or different conditions of testing. The condition of the surface has a high influence on the readings. Furthermore the type and the hardness of the aggregate and the carbonation degree, as it increases the surface hardness of the concrete, will have a big influence on the rebound number (Kim et al. (2009)).

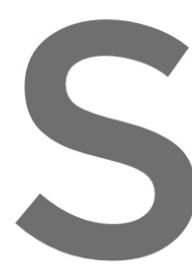

Measuring concrete with a Wenner probe the concrete surface. resistivity and strength and electrical resistivity
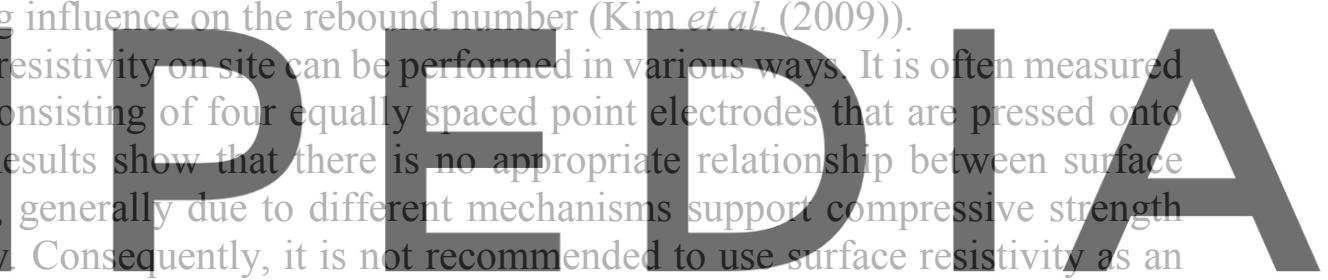

indicator for evaluation of compressive strength (Ramezanianpour et al. (2011)). Nevertheless,

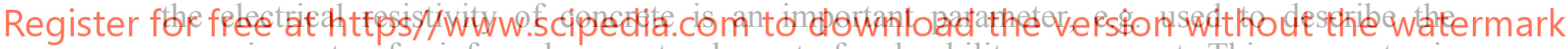
corrosion rate of reinforced concrete elements for durability assessment. This parameter is related to the water content, the cement type, the W/C-ratio of concrete and the hydration degree. Environmental conditions such as relative humidity and temperature also affect the resistivity of the concrete matrix.

Several researches have shown that the coefficient of air permeability $\mathrm{k}_{\mathrm{T}}$ correlates quite well with other standardized durability related tests (Jacobs et al., 2009). For instance, carbonation depth of concretes after 500 days of natural exposure correlates well with their $\mathrm{k}_{\mathrm{T}}$ values measured at 28 days: higher air permeability leads to higher carbonation rate. These concretes have W/C-ratios in the range 0.26-0.75 and are made with CEM I (except few mixes to which 5-8\% silica fume was added). Torrent et al. (2012) also found a rather good correlation between $\mathrm{kT}$ and results of the rapid chloride permeability test (ASTM C1202), with data originating from mixes with Portland cement, slags, fly-ashes and micro silica, and varying W/C-ratios (0.4-0.9). 


\section{Materials and Methods}

\subsection{Concrete Composition}

The study was initiated in 2013, with the casting of 14 non-reinforced slabs using 7 concrete mixtures with strength classes varying from $\mathrm{C} 12 / 15$ up to $\mathrm{C} 50 / 60$. For each mix two slabs (600 x $100 \times 100 \mathrm{~mm}^{3}$ ) were cast and tested (destructive compressive strength and various non- or semi-destructive techniques, as mentioned in (Craeye et al., 2017)). The properties of these mixtures are given in Table 1. These concrete mixtures are frequently applied in Belgium for different exposure classes. Limestone aggregates are used (max. grain size $22 \mathrm{~mm}$ ), except for mixture $\mathrm{C} 25 / 30$ (which used porphyry $8 \mathrm{~mm}$ ). Blends of three different cement types are selected: Portland CEM I 52.5R and blast furnace slag CEM III/A 42.5N - CEM III/B 42.5N.

Once this research project was finished, the slabs were stored in an unconditioned but sheltered outside environment. For this research study, the slabs are tested with an approximate age of 5.5 years.

Table 1. Concrete composition in different strength classes.

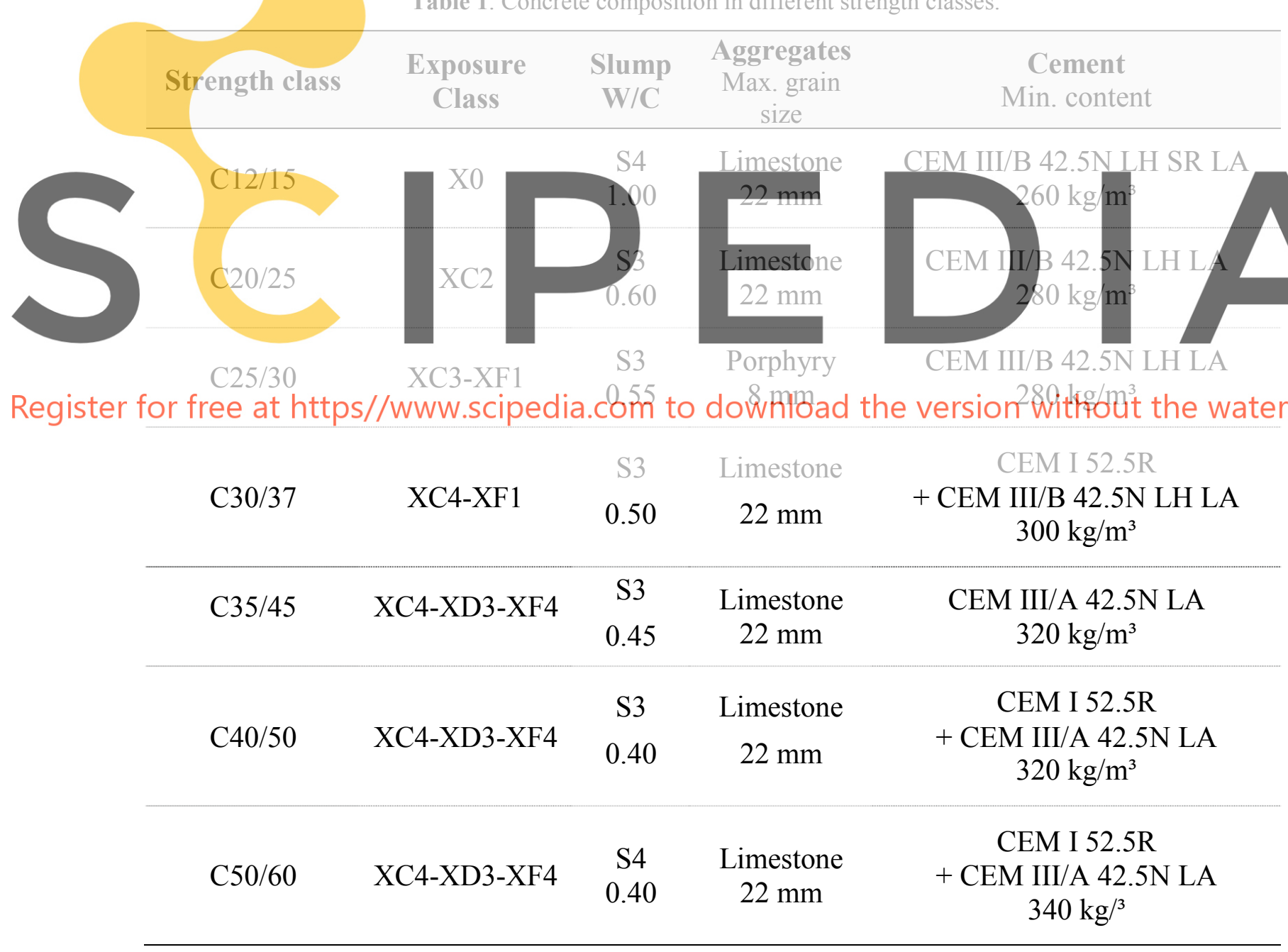




\subsection{Selection of (Non-)Destructive Methods}

Out of each slab 7 cores (diameter $100 \mathrm{~mm}$, height $100 \mathrm{~mm}$ ) are drilled to perform compressive strength, chloride migration and carbonation tests. To determine the actual compressive strengths of the concrete slabs, 3 cores are tested per slab, according to EN 12504-1. The core strength is converted into the equivalent cube compressive strength ( $*^{*}$ ccub150) by means of a shape factor (averaged value of 1.05, NBN B15-001).

Prior to the drilling the slabs are examined in a non-destructive way: ultrasonic pulse velocity (direct transmission), air-permeability, surface resistivity, and rebound hammer tests are executed, according to EN 12504-2, SIA 262/1, AASHTOT277 and 12504-4 respectively. The location of the tested area on the slab are identical for each test.

Chloride migration is determined in a non-stationary way, according to the NTBuild 492 regulations on 3 cores per slab. The depth of carbonation (or the carbonation coefficient) is determined on 1 core per slab, according to EN 14630, using 1\% phenolphthalein solution.

\section{Results and Discussion}

\subsection{Strength Assessment}

In Figure 1a) the results of the individual tests on both slabs per strength class are given and compared to the results obtained in 2014. There is a time difference of 5.5 years in between the 2014 and 2019 results. In general, there is a slight decrease in strength, except for C20/25.

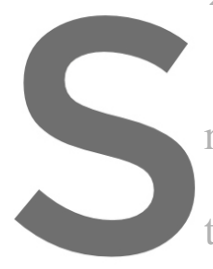

Lower strength loss

and C20/25, while for respectively.

The output of the equin the ultrasonic pulse velocity (di
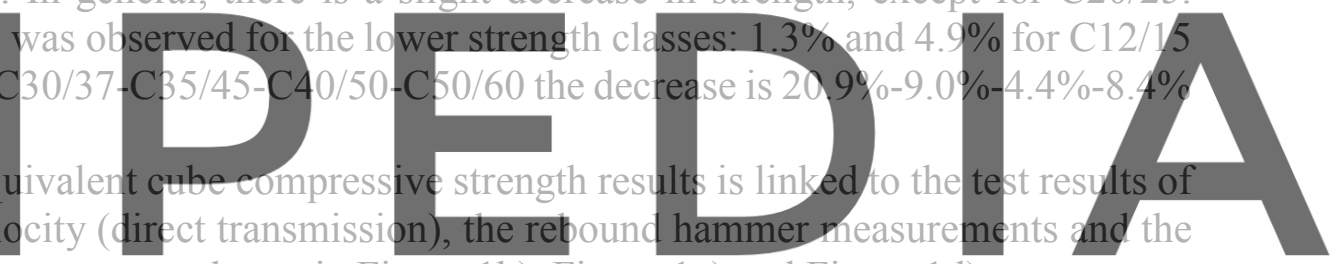

air permeability measurements, as shown in Figure 1b), Figure 1c) and Figure 1d).

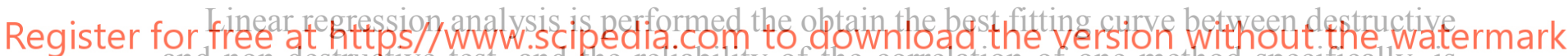
and non-destructive test, and the reliability of the correlation of one method specifically, is

quantified by means of the coefficient of determination ( $\mathrm{R}^{2}$-value) and the standard deviation

(shown in the graphs). A linear correlation exists between cube compressive strength and the ultrasonic pulse velocity and compressive strength and the rebound number, with comparable correlation $\mathrm{R}^{2}$ of 0.701 and 0.726 respectively. Compared to the 2014 study, there is a noticeable drop in $\mathrm{R}^{2}$ ( 0.957 for the rebound number, 0.886 for the ultrasonic pulse velocity): measurements on concrete surfaces that were subjected to environmental effects, have a significant lower linear coherence compared to tests performed on young concrete. It is known that carbonation has an effect on strength-hardness correlation (Kim et al., 2009) which is also identified in this study. There is a noticeable shift in the correlation in between the 2014 and 2019 correlation curve (Figure 1a)). Furthermore, the difference in between the correlation provided by the provider of the supplier and the one obtained in this research is worth mentioning. For a given strength, the rebound number increases due to carbonation, and this effect is more prominent for higher strength classes. Comparable conclusions can be drawn regarding the correlation in between strength and ultrasonic pulse velocity. However, the effect of carbonation is less clear. Furthermore, the compressive strength is inversely proportional 
with the air permeability (Figure 1c)): increasing the permeability of matrix leads to a decrease in strength. A good correlation is found in this project, $\mathrm{R}^{2}$ equals 0.83 .

As the resistivity meter is not designed for strength estimation, the measurements cannot be related to each other. In comparison with the 2014 study, it appears that the surface resistivity of the concrete slabs increased over a period of 5.5 years.

a)

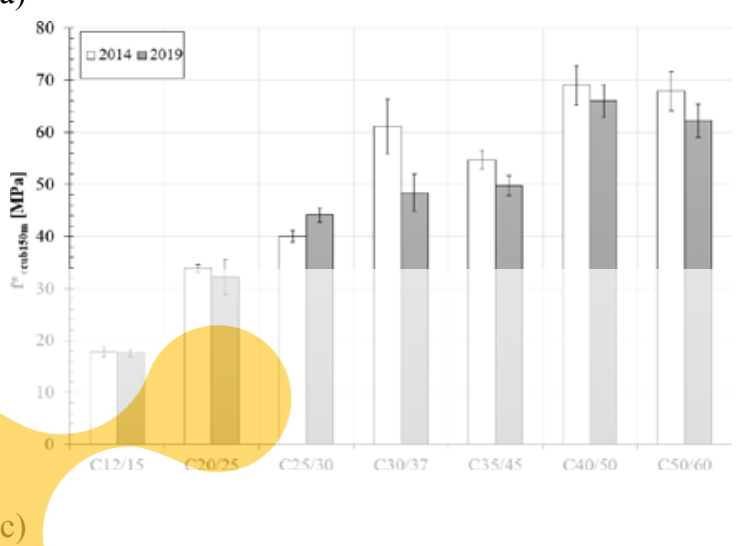

c)
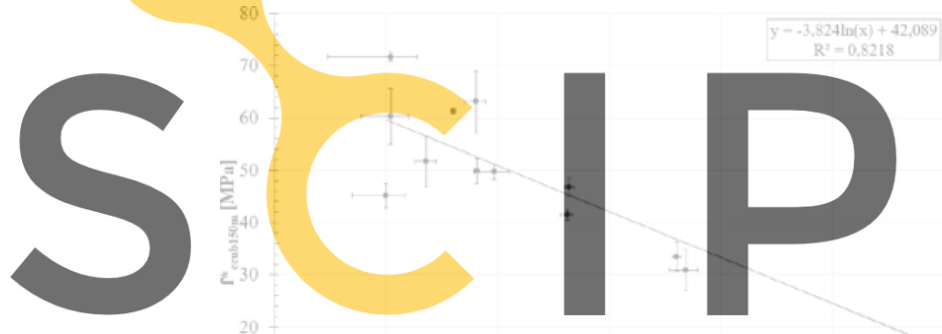

b)

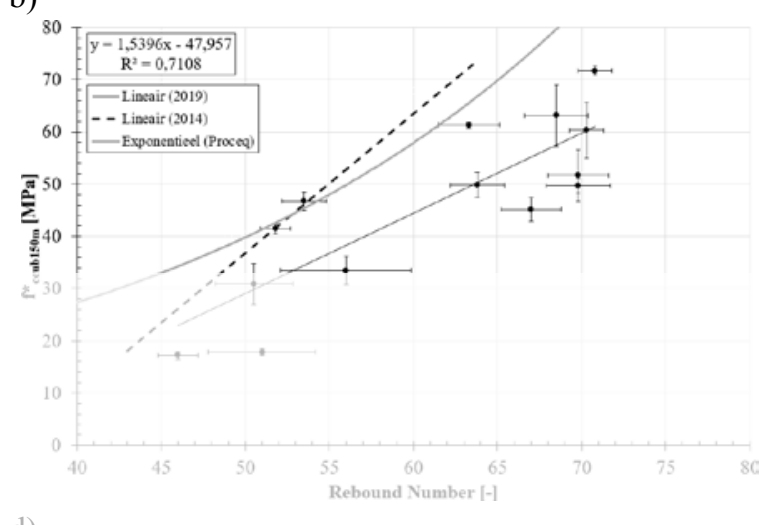

d)

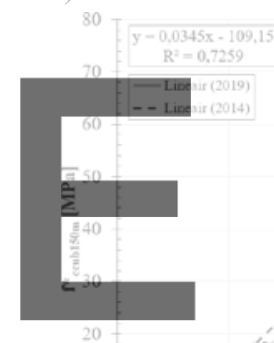

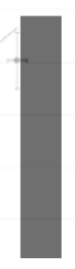

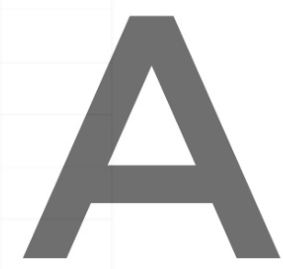

Register for free at https//www.scipedia.com to download the version without the watermark $0,001 \quad 0,010 \quad 0,100$

Figure 1. a) Equivalent cube compressive strength 2014-2019, b) correlation $\mathrm{f}^{*}$ cub150m-rebound number, c)

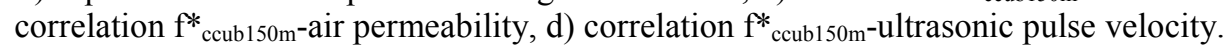

\subsection{Durability Assessment}

The depth of the carbonation and the chloride migration coefficient is determined destructively on the cores drilled out of the slabs. The results are presented in Figure 3a). The effect of the strength class is clearly noticeable. However, as the cement type has a decisive effect on durability and corrosion related properties such as carbonation and chloride migration (Hiemer et al. (2018)) a subdivision of the results is needed. The carbonation coefficient decreases with increased strength class for the slabs with a lower strength class concrete (C12/16 to C25/30) with blast furnace slag cement (CEM III/B) (Figure 3a)). For the higher concrete strength classes, using blends of Portland CEM I 52.5 and blast furnace slag CEM III, no effect of strength class on carbonation is found. The higher carbonation coefficient is noticed for the 
slabs with strength class C35/45. This is due to the single use of blast furnace slag CEM III/A, which is more susceptive to carbonation. It is known that carbonation leads to precipitation of $\mathrm{CaCO}_{3}$ which leads to an increase in hardness of the concrete surface and densification of the matrix, however without increasing the strength of the material. As carbonation of the concrete cover increases, the permeability of the matrix increases (Figure 3c)) and a decrease in pulse velocity can be identified (Figure 3b)). The permeability of concrete has an effect on the speed of propagation of the ultrasonic pulse, which is shown in Figure 3d). Elements with high permeability have a lower pulse velocity, mainly due to the scattering of the pulse through air present in the pores. It is important to note that the use of the air permeability meter can be a good alternative for the ultrasonic pulse velocity tester.

No trend is noticeable regarding effect of strength class on chloride migration (Figure 3a). The cement type has a decisive effect on transport of chlorides through concrete: using blast furnace slags has a more positive effect on chloride migration compared to the strength class. Finally, a higher chloride migration is found in case of higher air permeability or surface resistivity (Figure 3e), Figure 3f)), however the scatter on the results is quite high, and therefore a clear correlation cannot be established.
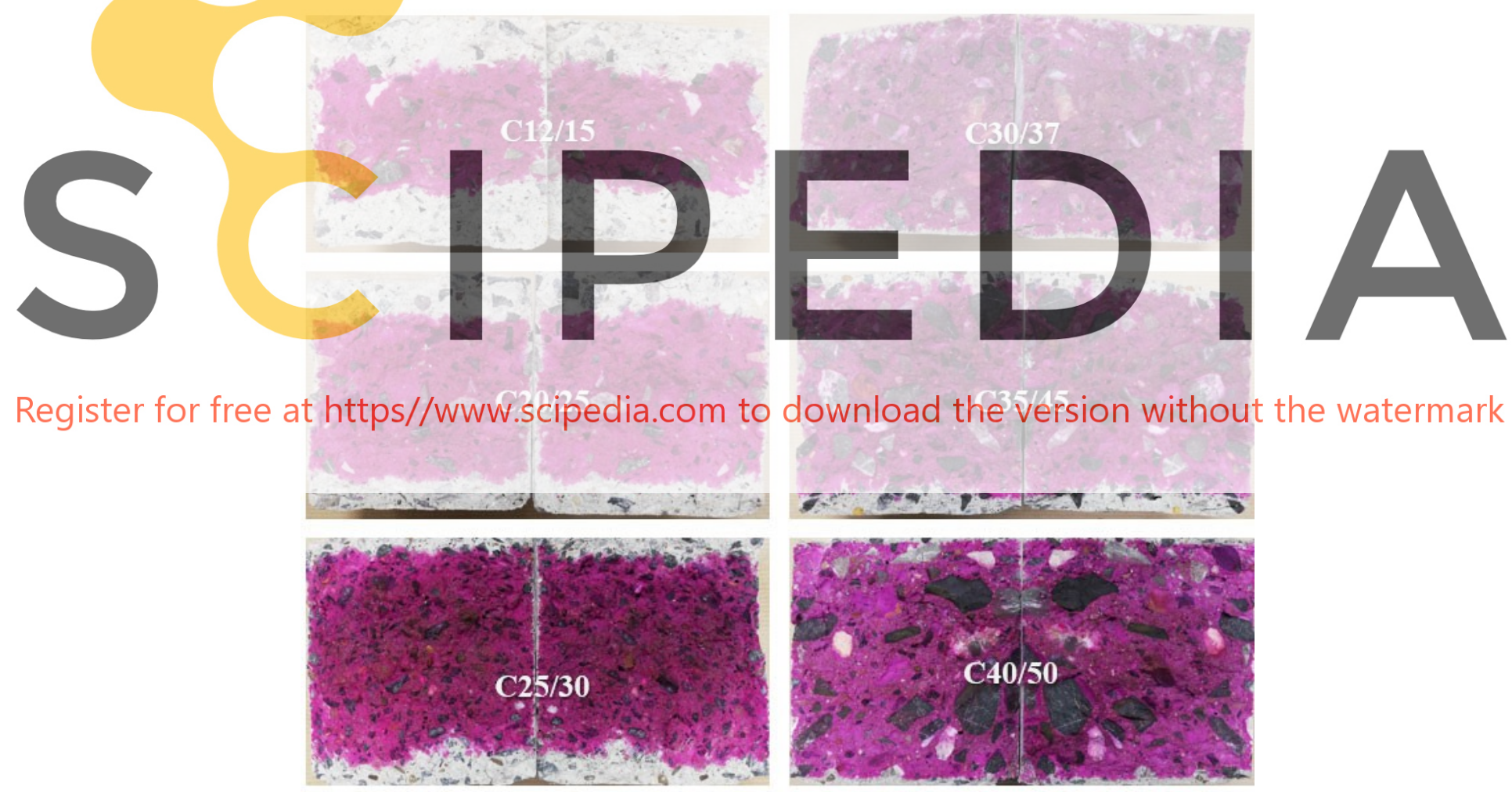

Register for free at https//www.scipedia.com to

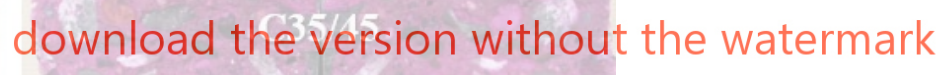

Figure 2. Carbonation depth of concrete with different strength classes.

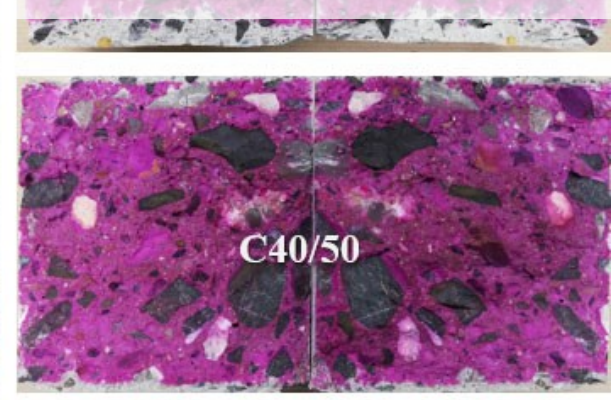


a)

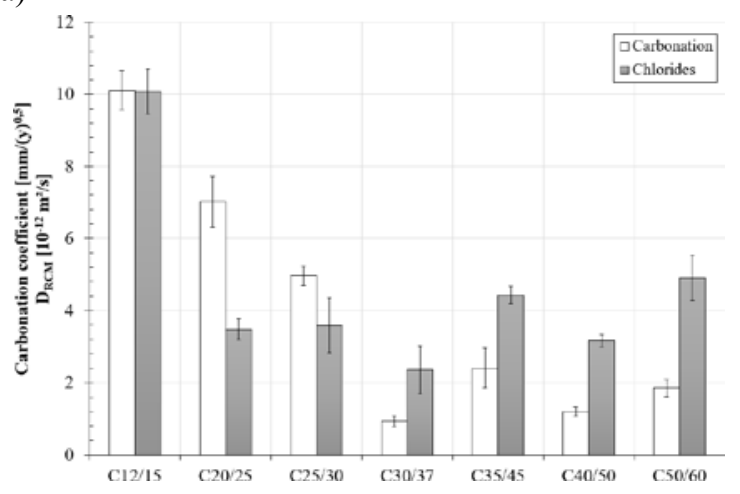

c)

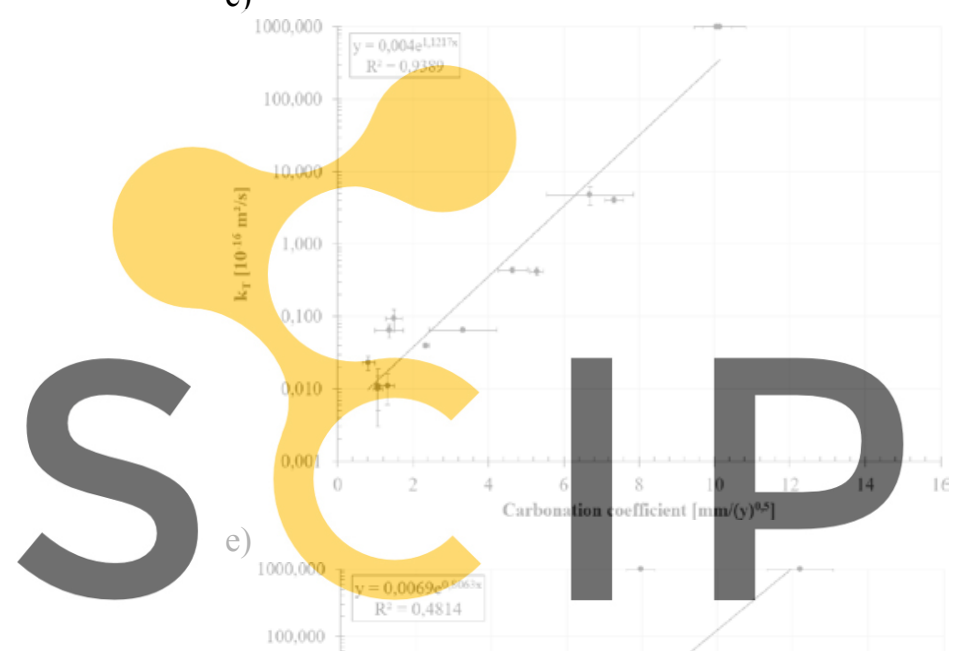

b)

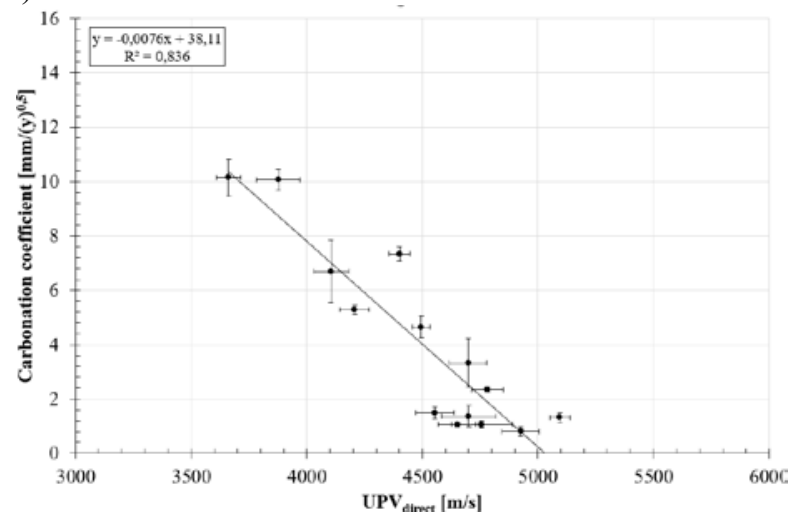

d)

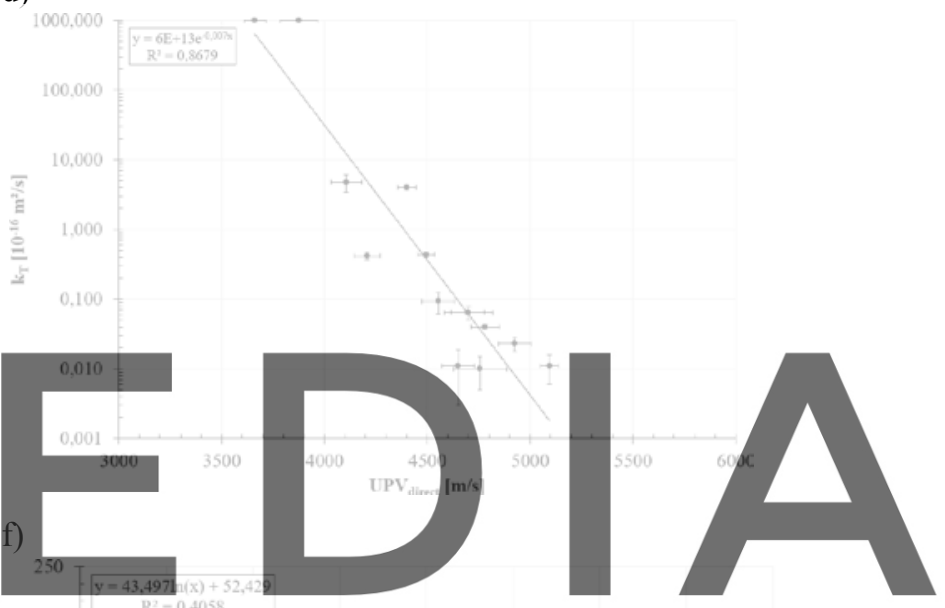

Register for free at https//www.scipedia.com to download the version without the watermark
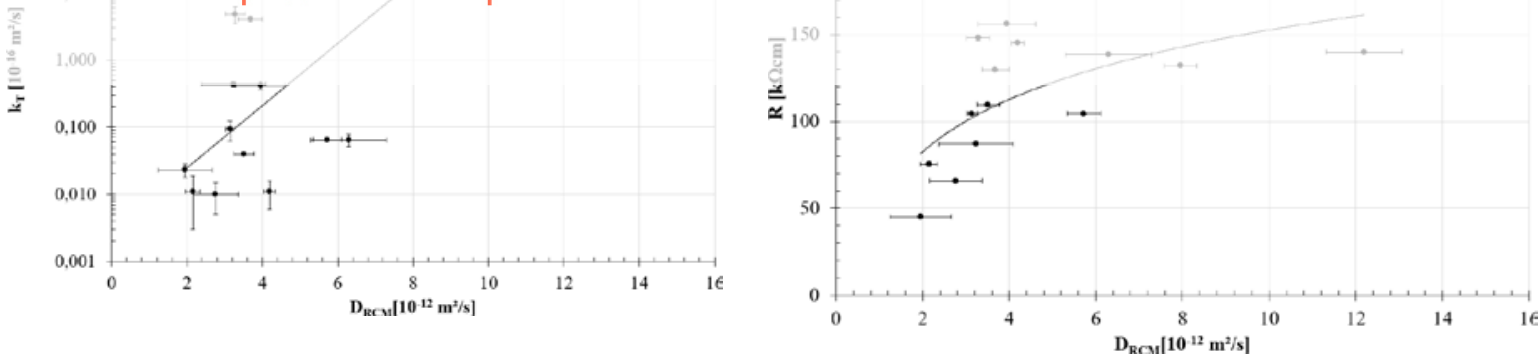

Figure 3. a) Results of carbonation coefficient and chloride migration $\mathrm{D}_{\mathrm{RCM}}, \mathrm{b}$ ) correlation carbonation coefficientultrasonic pulse velocity, c) correlation air permeability-carbonation coefficient, d) correlation air permeabilityultrasonic pulse velocity, e) correlation air permeability- $\mathrm{D}_{\mathrm{RCM}}, \mathrm{f}$ ) correlation surface resistivity- $\mathrm{D}_{\mathrm{RCM}}$. 


\section{Conclusions}

In this study an experimental program is conducted on concrete slabs of different strength classes intended for various exposure classes, based on a limestone aggregate matrix. The plates have an age of 5.5 years, and are also characterized at younger stage (in 2014). Destructive core drilling and testing and several non-destructive techniques are used to assess strength and durability related properties of the slabs.

A slight strength decrease is found after 5.5 years with higher strength loss is for higher strength classes. Furthermore, the strength is linear proportional with surface hardness and ultrasonic pulse velocity and inversely proportional with air permeability. Compared to the results of 2014 (i) higher coefficient of determination on the obtained correlation curves is found and (ii) a shift on the correlation curves is noticeable, linked to the aging effect due to carbonation. This aging effect is more pronounced for the rebound hammer results. The effect of strength class on carbonation rate is clearly noticeable for slabs of lower strength classes (up to $\mathrm{C} 25 / 30$ ). For higher strength classes the effect of cement type is more pronounced.

A linear correlation with high coefficient of determination is found between carbonation coefficient, air permeability (directly proportional) and ultrasonic pulse velocity (inversely proportional). Note that the air permeability test is a good non-destructive alternative for the ultrasonic pulse velocity test: elements with high permeability have a lower pulse velocity, mainly due to the scattering of the pulse through air present in the pores.

Finally, no trend is noticeable regarding effect of strength class on chloride migration and a

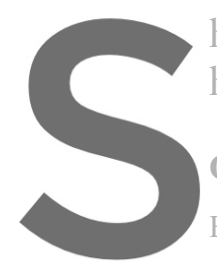

higher chloride migrati

however a clear correlatin

ORCID
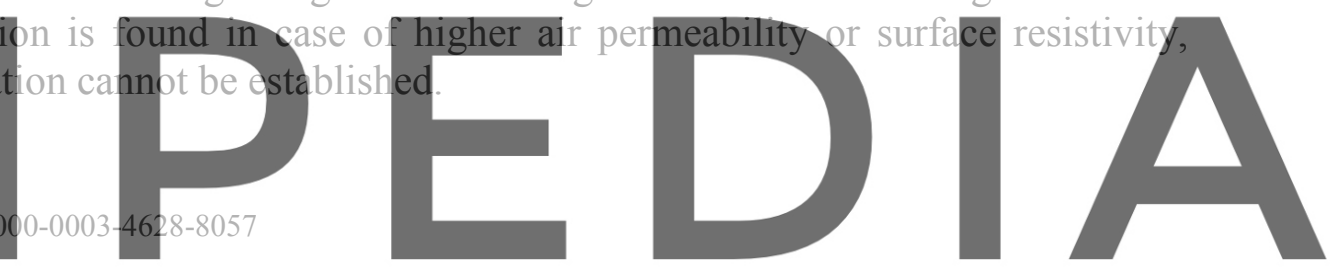

References

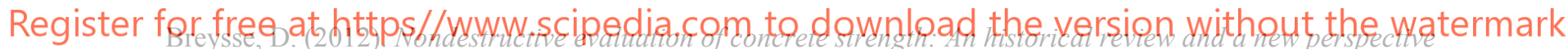
by combining NDT methods, Construction and Building Materials, vol. 33, pp. 139-163.

Craeye, B., van de Laar, H., van der Eijk, J. and Lauriks, L. (2017). On-site strength assessment of limestone based concrete slabs by combining non-destructive techniques, Journal of Building Engineering, vol. 13, pp. $216-223$.

Hiemer, F., Jakob, D., Kessler, S. and Gehlen, C. (2018). Chloride induced corrosion in cracked and coated concrete: from experimental study to time-dependent modelling, Materials and Corrosion, vol. 69, no. 11, pp. 1526-1538.

Hobbs, B. and Tchoketch Kebir, M. (2007). Non-destructive testing techniques for the forensic engineering investigation of reinforced concrete buildings, Forensic Science International, vol. 167, no. 2-3, pp. 167-72.

Jacobs, F., Denarié, E., Leemann, A. and Teruzzi, T. (2009). VSS Report 641, OFdR, Bern, Switzerland.

Kim, J.-K., Kim, C.-Y., Yi, S.-T. and Lee, Y.(2009). Effect of carbonation on the rebound number and compressive strength of concrete, Cement and Concrete Composites, vol. 31, no. 2, pp. 139-144.

Maierhofer, C., Reinhardt, H.-W. and Dobmaan, G. (2010). Non-destructive evaluation of reinforced concrete structures, Woodhead Publishing in Materials, CRC Press, UK.

Ramezanianpour, A.A., Pilvar, A., Mahdikhani, M. and Moodi, F. (2011). Practical evaluation of relationship between concrete resistivity, water penetration, rapid chloride penetration and compressive strength, Construction and Building Materials, vol. 25 , no.5, pp. 2472-2479.

Solís-Carcaño, R. and Moreno, E.I. (2008). Evaluation of concrete made with crushed limestone aggregate based on ultrasonic pulse velocity, Construction and Building Materials, vol. 22, no. 6, pp. 1225-1231.

Torrent, R., Denarié, E., Jacobs, F., Leemann, A. and Teruzzi, T. (2012). Specification and site control of the permeability of the concrete cover, Materials and Corrosion, vol. 63, no. 12, pp. 1127-1133. 